\title{
Conceptual Model and IT System for Organizational Capability Management
}

\author{
Philippe RAUFFET, Catherine DA CUNHA, Alain Bernard \\ \{philippe.rauffet; catherine.da-cunha; alain.bernard\}@irccyn.ec-nantes.fr \\ LUNAM Université, Ecole Centrale de Nantes, IRCCyN UMR CNRS 6597 (Institut de Recherche en \\ Communications et Cybernétique de Nantes), 1 rue de la Noe BP 9210144321 Nantes Cedex 3 France
}

\begin{abstract}
Organizational Capability Approach opens new perspectives for developing and sharing organizational competencies around the strategy of globalized companies. This paper explores this approach and aims at implementing it practically. Thus, it provides a conceptual model named C-Makers, which is then used in the design of IT solutions to manage organizational capabilities (mechanisms for transfer, assessment, renewal). These propositions are then experimented on with the case of an automotive supplier, Valeo Group.
\end{abstract}

Keywords. Competency management, Industrial engineering, Organizational capability, Enterprise Modelling

\section{Introduction}

Facing increasingly turbulent environments, globalized organizations follow the SCP paradigm. This theory assumes that market Structure induces changes on enterprise Control, which explains Performance (Porter, 1979). Thus, companies adopt agile structures, becoming distributed and multi-hierarchic organizations in order to resist external perturbations. This structural complexity triggers off issues of performance management: it is harder to maintain operational excellence (how to produce goods or services with the same quality level whichever plant delivers them) and functional interoperability (how to guarantee cohesion, how to enable the equifinality and the synergy of all entities around common projects). From this diagnosis, globalized enterprises understood that they had to develop their organizational competencies, and share them amongst all their organizational components.

Many scientific approaches explored this industrial challenge on different levels (individual, collective and organizational competencies), from engineering sciences with the works on competency engineering and enterprise modeling (Harzallah et al., 2006, Boucher et al., 2007) to management sciences with the application of resource-based theory to the fields of knowledge and competency (Grant, 1996, Hamel and Prahalad, 1990) as well as the research on practices transfer (Szulanski, 2006). Among them, the Organizational Capability Approach and attempts to apply it practically, emerged (Saint Amant and Renard, 2004). Whilst this approach enables another point of view in order to develop organizational competencies in globalized structures, its deficiencies prevent conceptual models and IT solutions from structuring a complete methodology.

This paper aims at building a formal model called C-Makers and IT solutions to support the Organizational Capability Approach. The first part is focused on the concept of Organizational Capability, its management mechanisms and the limits of existing methods and tools. The second section provides our formal model for Organizational Capability and underlines how its key concepts could exceed the identified limits. This model is then used for the proposal of new IT solutions in order to manage organizational capabilities, which are 
then tested on Valeo Group. The benefits of the formal model on the approach, as well as the experimental results, are then discussed.

\section{Related Works}

The Organizational Capability Approach is studied in this first part, in order to extract its key points and to understand its management mechanisms. Then, the limits of current methods and tools are analyzed so as to orientate our IT proposal.

\subsection{A multidisciplinary concept for developing organizational competencies}

Organizational Capability Approach stands on the border between management sciences and industrial engineering. It is therefore necessary to define the concept by highlighting its impact on each discipline, particularly in the area of Resource Based View and Competency Engineering.

\subsubsection{Organizational Capability and Resource Based View}

Organizational Capability Approach is an emerging theory emanating from management sciences. It is part and parcel of Resource Based View, which focuses on the internal identification of resources, knowledge and competencies that are considered as strategic, that is to say, available for creating a sustainable, competitive advantage for organizations (Hoopes, Madsen, Walker, 2003). Moreover, it is opposed to an "over elitist" view of resources, which considers only the valuable, rare, inimitable, non-substitutable resources (Barney, 1991). It answered to this criticism through a "managerial" view, aimed at developing a competitive advantage through the combination of resources that are not strategic when they are taken alone.

Proponent of this approach, (Saint-Amant and Renard, 2004) synthesize the definitions of organizational capabilities as "know how to act, a potential of action resulting from the combination and the coordination of resources, knowledge and competencies of the organization, and which can be expressed through the activities of the value flow, to fulfill strategic objectives".

This definition highlights some significant characteristics:

- Key organizational aptitudes: organizational capabilities constitute the key aptitudes that a company must develop and assess to gain competitive advantage and to determine the status of its strengths and its weaknesses (de Pablos \& Lytras, 2008).

- Potential performance built by knowledge acquisition and resources synergy: Organizational capabilities emerged from the synergies of organizational resources. They continuously progress thanks to the acquisition of knowledge and competencies (generally modeled under the form of corporate best practices). They are thus related to organizational learning (Lorino, 2001) and therefore knowledge acquisition evaluation can be regarded as a means to assess Organizational Capabilities as "potential performance".

- Driver of real performance expressed in activities: Furthermore, organizational capabilities can be expressed through the value flow. That is to say that their use should generate an improvement in the performance of the activities of organization (Rauffet, 2009). Performance indicator trends can therefore provide a means to assess organizational capabilities as "real performance" drivers.

- Local and shared capabilities: All the organizational resources are involved in achieving corporate objectives. On a local level, organizational capability is the synergy of human, physical and structural resources of an entity around the defined strategic objectives. At upper levels, organizational capability is the synergy of entities that develop and share the same corporate practices and therefore the same organizational capabilities (Lebas, 1995).

These properties clearly emphasize that organizational capability must be viewed as a construct related to knowledge acquisition and resource synergy and oriented by the organizational strategy. Moreover, the duality between potentiality (organizational capabilities can induce a performance improvement) and reality (the results of activites expressed the use of organizational capabilities) is a key point which must be kept in 
mind in order to model and manage organizational capabilities.

\subsubsection{Organizational Capability and Competency Engineering}

Even if they come from management sciences, Organizational Capability Approach and concepts could be studied with the background of Competency Engineering. Competency is consensually defined as the aptitude of an actor to put into practice a set of knowledge and environmental resources in a specific context in order to achieve certain objectives (Amherdt, 2000). It can be considered according to the level of the concerned actor, which can be:

- individual; relative to an elementary actor, such as human resource competency, and to some extent, process capability and capacity for machines.

- collective; for a single organizational entity (e.g. the competency of a purchasing service in a plant to buy raw materials of a good quality for a good price (Vaudelin, 2002)) or for the whole organization (e.g. the competency of the purchasing department of a company to impose a quality policy on all its suppliers, which can become a core competency of the company (Sanchez et al., 1996)).

The concept of organizational capability seems very close to the competency concept: They are both an "aptitude", they are both based on the combination and use of knowledge and resource and are both finalized (i.e. they aim at achieving an objective through an activity).

Nevertheless, the competency concept is still often oriented by "individual" considerations and by "process" definition and its homothety to organizational levels is sometimes misunderstood and misapplied in companies. Indeed, (Amherdt, 2000) and (Cullen Coates, 2008) observed that in many companies, organizational competencies management is often reduced to simply focus on employee skills and on the defined goals and processes of the firm, rather than the compelling cross-company core competencies that drive integrated business execution and management alignment.

Organizational Capability Approach would be a means to overcome this reducing trend. The nature of the concept therefore allows for the proposal of a different point of view, which is oriented by organizational aspects and the link between resources and strategy from the onset, without necessarily considering the definition of processes. A competency can thus orientate the definition of processes, instead of uniquely being a criteria for the allocation of resources on existing processes.

1.2. Organizational Capability Management: transfer, assessment and renewal mechanisms

The interest of Organizational Capability Approach in the field of management sciences and competency engineering is highlighted above. The following paragraphs aim at synthesizing its management mechanisms. As emphasized by (Lorino, 2001) in the previous listed properties, Organizational Capability is the product of an organizational learning process. This leads to a better synergy of a set of resources, knowledge, and competencies around strategic objectives. Thus, the definition of Organizational Capability Lifecycle inherits from works concerning organizational learning, knowledge lifecycle and best practices transfer. This exploration details the mechanisms for transferring, assessing and renewing Organizational Capabilities.

\subsubsection{Transfer mechanisms, from acquisition to appropriation}

Organizational learning is defined as a "collective endeavor which aims at increasing, in a continuous and active way, individual and organizational knowledge and skills” (Senge, 1990, Garvin 2008). According to (Yeung, 1999), it can be considered as a capability which "enables to generate ideas (innovation), to detect and generalize them (conceptualization) then to transfer them through all the organizational layers (transfer), with the aid of initiatives and management practices". The first part of Yeung's definition, focused on a "learning capacity", is similar to the analysis of (Diani, 2002), who writes about an ability to "create new 
knowledge and to transform this one into competencies for organization”. This twofold challenge is depicted by the purple boxes in Figure 1. An important matter in organizational learning in distributed organizations is the codification of local innovations, the transfer of this knowledge, sometimes known as "good practices", and the use of these practices to increase the "organizational capabilities" of each entity. In this framework, (Szulanski, 2006) describes five processes. They explain the different transformation stages from a local innovation into conceptualized organizational practices and then into a transferred organization capability (Figure 1, green boxes):

- Acquisition: An organizational need is identified and knowledge is found locally (by expert or operational workers) to solve this requirement.

- Adaptation: Knowledge is modified and combined, to become an organizational knowledge and to be adapted to future learners.

- Application: This adapted knowledge is communicated and transferred to the learners.

- Acceptation: Animation around the applied knowledge must be done so that knowledge is effectively acquired by learners and becomes an organizational capability.

- Appropriation: Organization is mature on the transferred knowledge and skills, and entities are autonomous on them. They adapt them locally or propose modifications to group.

These five processes are actually very similar to the SECI model (Nonaka, 1994), as emphasized by the green boxes in Figure 1. There is only a slight difference brought by the Szulanski processes. Indeed knowledge "externalization" is derived in two different processes, "application" and "acceptation”, which play on the "individual/organization" duality. Thus organizations have to share the practices they want to implement, but they also have to check if these practices are understood and used by operational subsidiaries.

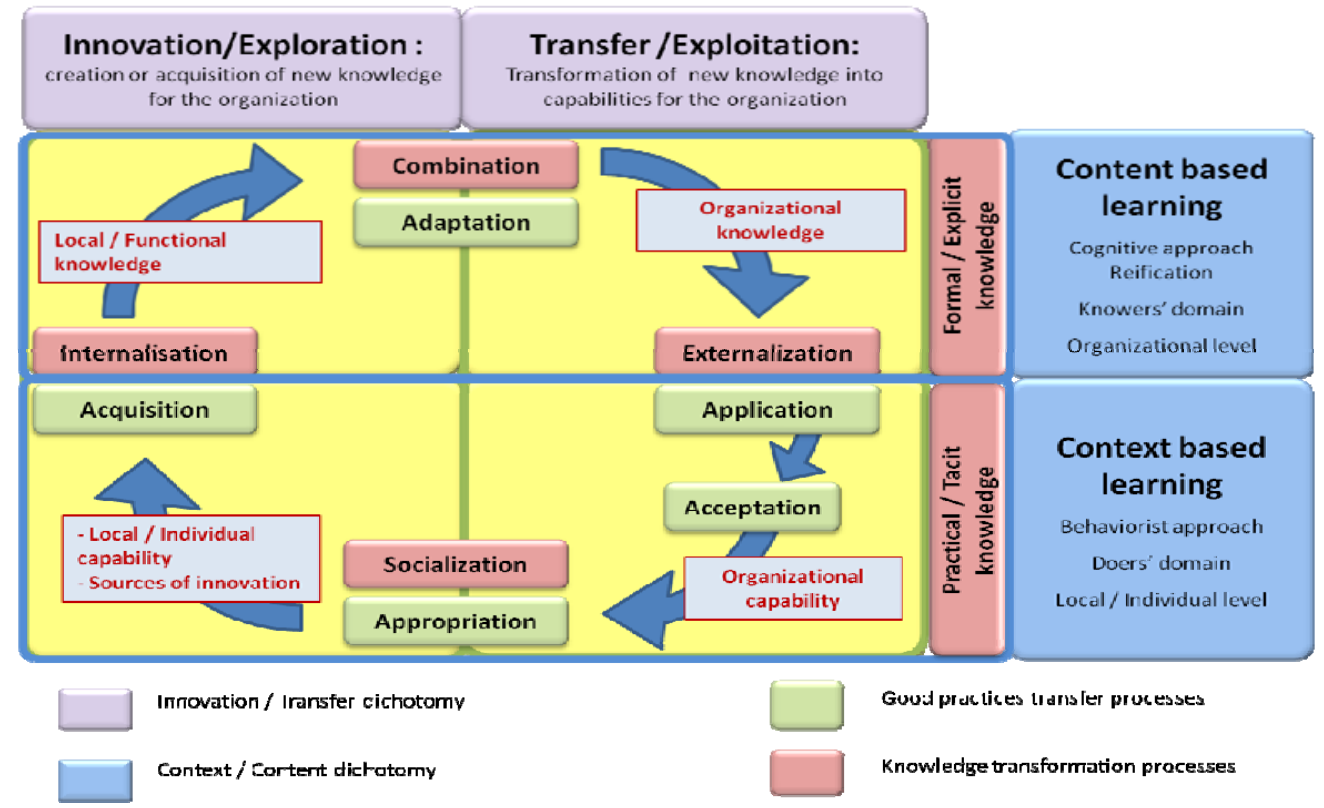

Figure 1. Organizational Capability Lifecycle

A second layer could be added to this analysis. As emphasized by (Rauffet 2009), learning processes can also be divided into two approaches, as shown above (Figure 1, red box): (1) A cognitive approach, based on knowledge and capability codification, which is also called "reification". It is the part dedicated to the "knowers", who model and make knowledge formal; (2) A behaviorist approach, based on the learning and the work context, which is more focused on Nonaka's process of socialization. It is the part dedicated to the “doers”, who use knowledge as capabilities to do their tasks.

The synergy of cognitive and behaviorist approaches is essential for organizational learning in extended organizations. The formal work of knowledge modeling is the fundamental support for communicating on and managing the development of organizational capabilities. This is a way to clarify the message that an 
organization wants to transmit to its entities, and to mobilize these entities around key objectives. In another way, the informal knowledge sharing is vital for adapting corporate practices to the local and operational context. It is also an enabler for creating an innovation dynamic, where the "doers" have the possibility to improve the guide by giving a part of their experience to the organization. In other words, learning must take place between standardization and diversity. It is therefore necessary to support that through some renewal mechanisms (cf. 1.2.3).

Beforehand, the following paragraphs focus on the particular issue of using this transfer of good practices libraries to manage and assess Organizational Capabilities.

\subsubsection{Assessment mechanisms, from practices to organizational capabilities}

As for competencies (Harzallah et al, 2006), Organizational Capabilities assessment is based on the comparison between what companies require and what entities acquire (Saint Amant and Renard, 2004). The notion of good practices (discussed in the previous section about transfer) is not only a learning means to structure and to deploy organizational capabilities from knowledge experts to operational workers. Practice is also an analysis unit to describe what is required and to measure the acquisition and the development of organizational capabilities.

Thus, the assessment of Organizational Capabilities can be carried out by comparing the practices used by organizational entities and the practices libraries deployed by the organization. These libraries are sometimes very structured (e.g. the Capability Maturity Model Integration (SEI, 2011) proposes a grid to store practices according to process areas and maturity levels).

Moreover, this assessment must be consolidated at every organizational level: the synergy of resources, knowledge and competences is observed on the operational level but the interest of Organizational Capability Approach is to guarantee the link between strategy and operations (Saint Amant and Renard, 2004). Thus, the different local assessments have to be aggregated for product sectors, for geographical areas, for functional networks (in order to verify the deployment and sharing of organizational capabilities) as well as for the whole organization (in order to diagnose the alignment between local endeavor and strategy).

\subsubsection{Renewal mechanisms, towards a crossed learning and a better appropriation}

The management of organizational capabilities is sometimes reduced to a transfer of good practices, where local innovations are detected once and modeled in some standards that learners attempt to continuously comply with. To some extent, people have to adapt themselves to what is asked of them but they cannot adapt the standards to what they are really faced with. This learning configuration aims at quickly aligning entities on organizational practices, but it can trigger off resistance to change and a bad appropriation of required knowledge by entities. It is why it is important to boost feedback from the entities, loop all the transfer processes, avoid them becoming overly normative and allow for the acquisition of new knowledge.

To guarantee the appropriation of practices by the "doers" (and make the tasks "fulfilled"), acceptation mechanisms must be understood. As explained by (Guillevic, 1993), this acceptation process depends on two factors (cf. left side of Figure 2):

- The intrinsic attributes of the learners, which reduce what the organization wants (the "expressed tasks") into what learners are capable of doing (the "implied tasks")

- The characteristics of the learning environment, which reduce what the organization wants into what learners are allowed to do (the "specified tasks")

To limit the restriction effects generated by these factors, it is necessary to adapt or to transform the content of the guide or the context of the application. In this framework, (Argyris and Schoen, 1978) introduced the "double-loop learning" principle (cf. right side of Figure 2). This allows for the sustainability of the organizational learning system, by letting the "doers" propose innovation and call imposed practices into question. As underlined by the "performance's causal model” from (Burke and Litwin, 1992), the "doers" 
are not only in a "transactional" logic (simple loop), where they look to adapt their behavior to match the allocated objective. They are also able to have a "transformational" impact (second loop) on what they are asked to do, allowing organizations to acquire new knowledge from local ground, around the basis of existing transferred practices. This double loop learning is obviously based on the distinction between the knower (the one who teaches and constitutes the practices library, at a strategic level) and the doer (the one who learns and uses the practices to achieve his/her tasks at an operational level). More recently (Le Boterf, 2003) added a third learning loop internal to the process of appropriation (not represented in Figure 2 because there is no communication between strategic and operational levels): The doer can also become a knower for other doers at operational level. So horizontal learning is developed in addition to the vertical learning.

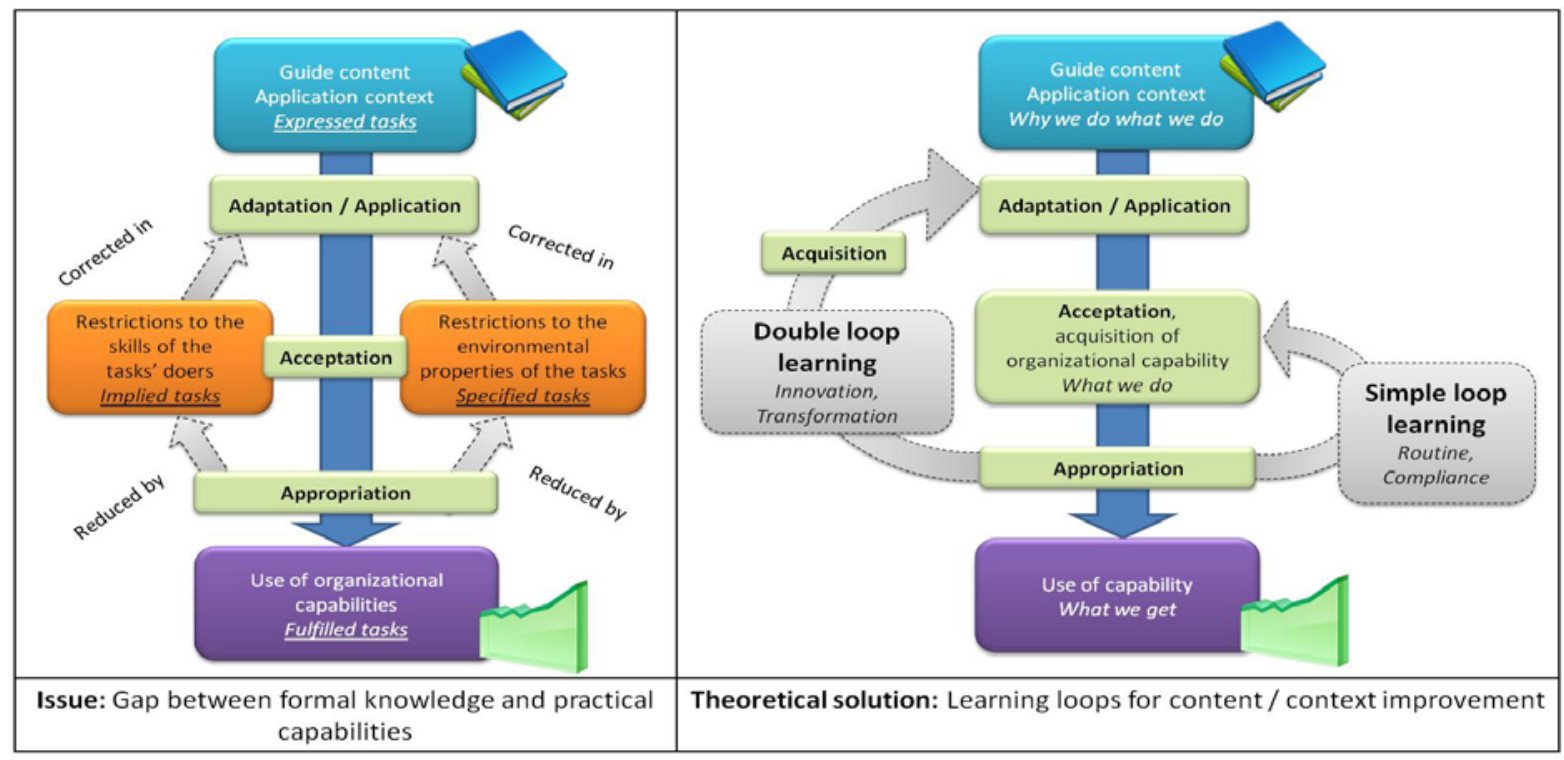

Figure 2. Renewal mechanisms for Organizational Capability management

Three kinds of necessary mechanisms were identified in the literature to robustly manage Organizational Capability Approach. (1) Transfer allows for the deployment of Organizational Capabilities by structuring identified practices around strategic objectives and deploying them to the operational ground in a top-down process. (2) Assessment enables to diagnose the strengths and the weaknesses of an organizational entity (from a plant to the whole organizational) on required organizational capabilities, and to decide if it is mature enough to seize new opportunities. (3) Last of all, renewal aims at keeping horizontal and vertical innovation and dialogue in order to prevent the transfer mechanisms from becoming a managerial straightjacket. The next section studies how these three mechanisms are implemented in existing methods and tools.

\subsection{Existing methods and limits}

There are many methods and tools, both from academy and industry, which aim at managing organizational competencies. They follow the same objectives as the Organizational Capability Approach, even if the point of view and the managerial processes can be different.

The following paragraphs provide an overview of the methods and studies if they are sufficient to support the previously defined mechanisms. We classify them into three categories:

- from competency engineering, we distinguish (1) the process-oriented methods and (2) the resourceoriented methods, which differ by the kind of considered competencies (hard ones versus both hard and soft ones) and their links to the existing definition of activities.

- from management sciences, we can list some (3) Organizational Capability methods, which offer partial development to instrument the Organizational Capability Approach. 
On the organizational level, the "process-oriented" approach is supported by some quality methods. This details a set of standards in order to design a framework for developing and assessing organizational competencies after modeling the firms' processes. We can quote ISO norms for Integrated Management Systems: CMMI (SEI, 2011) and ITIL libraries (ITIL, 2011) for Information Systems and SMEMP (Gonzalez-Ramirez et al. 2008) for Project Management. These methods propose requirements and guidelines to build this competency framework around some process areas, and some of them also structure the competency assessment around a learning path (e.g. CMMI with the maturity logic).

Interesting tools must be kept in mind: they enable to structure and deploy practices libraries, and therefore to support the transfer mechanism presented in section 1.2.1. However, the standpoint of these methods can be criticized for their decreasing consideration of organizational competencies. Indeed, the "process oriented" approach tends to qualify competencies according to the predefined processes it has to support (Armistead, 1999). The notion of competency therefore becomes a criterion to allocate entities to the organizational activities. It is often reduced to a kind of "technical competency" or "hard competency", based on the theoretical knowledge and the know-how of operations by actors (McClelland, 1973, Amherdt, 2000). In this case, competency framework must be redefined as soon as the firm's activities change. Furthermore, the renewal mechanisms are hard to implement because of the normative logic defended by these methods, often considered as standards.

\subsubsection{Resource-oriented organizational competencies management}

The "resource oriented" approach is supported by research works on competency engineering. (Boucher, 2003) (Harzallah and Vernadat, 2007), (Bonjour et al., 2002) (Houé and Grabot, 2007) (Hiermann and Hofferer, 2003) propose models and frameworks (detailed in section 2.1) to describe and assess competencies according to organizational aspects (closer to knowledge areas than processes) and on different organizational levels. These methods allow for the determination of the new opportunities provided by an individual (e.g. the polyvalence of an individual who can be allocated to different workstations), a group (e.g. the agility of a team which can be reconfigured on different projects) or an organization (e.g. the development of a new core competency in the management of composite products which can open new market).

So the approach is based on a broader definition of competency. This aims at identifying and developing it as a capital of knowledge used to master the different aspects of the task that is given to the actors, whatever its organizational level (Tarafdar and Gordon, 2007). The competency is then defined in the longer term: It does not only focus on technical aspects (and on the adequacy of an actor's skills to tasks) but also on the potential value which can be developed by the actor and reinvested in the current and future processes. It is more a kind of "behavioral competency" or "soft competency" (Amherdt, 2000) based on relational and learning aspects, which enable the mastering of "business knowledge". Thus competency would be more adaptable and could be used whatever the operational processes chosen.

Nevertheless, the tools of the literature are either (1) overly oriented by an individual definition of competency that is translated at organizational levels by a difficult and sometimes non systemic aggregation or (2) more interested in the listing of organizational competencies and their global assessment without defining precisely how they are built from good practices and how they are practically developed in the different organizational entities. Because the analysis unit is the individual or the organizational competency rather than what explains and builds its development (i.e. identified in section 1.2.1 as the good practices), the transfer mechanism is not really supported. Moreover, renewal is weak for the same reasons (the underdetailed practices are difficulty improvable).

1.3.3. Organizational Capabilities management 
The methods focusing on the implementation of the Organizational Capability are very recent. We can mention the Capability Development Method, supporting IT administration, developed by (Saint Amant and Renard, 2004), the CBEA (Webb, 2006), or the CPX used by English SMBs to integrate Information Systems that was proposed by (Duhan et al., 2005).

These methods reuse the same standpoint as the resource-oriented methods but at an ever macroscopic level. The organizational dimension is present from the onset (the logic of aggregation from individual competencies is not considered). Moreover, they focus on the problem of governance and alignment to reinforce the link between strategy and operations. Thus, they propose global framework listing and the structuring of the key core competencies that a company must have on some specific strategic domains. For instance, (Saint-Amant and Renard, 2004) suggests that Information System strategy is supported by some macro organizational capabilities (project management, risk management, organizational transformation, portfolio management), which can also be decomposed into other medium organizational capabilities (project management is supported by cost, quality or RH management). The strategy managers use this global and not very operational modeling of organizational capabilities to assess their organizations according to maturity levels. However, the elements to prove and justify the levels are not explicated and the assessment is sometimes subjective (dependent on the viewpoint of the manager).

These methods are not very mature. They stand at a very high level (necessary to keep the link with strategy) but they do not succeed in practically implementing the Organizational Capability Approach (the link to operations is not supported, because practices are not defined and detailed). The mechanisms for transfer and renewal are therefore absent or very weak. Furthermore, the Organizational Capability methods do not provide IT platforms to automate the management of the approach, which is necessary in the context of distributed, globalized organizations.

\subsection{Towards an IT support for managing practically organizational capabilities}

As emphasized by this overview on related works, some key points must be considered as invariant to support a reliable management of Organizational Capability Approach:

- the management of Organizational Capabilities Approach is based on three main mechanisms: transfer, assessment and renewal;

- literature emphasized some principles and guidelines to design and to structure the development of an organizational capability: (1) it is necessary to guarantee the link between strategy and operations; (2) good practices could be an analysis unit to structure and assess capabilities (3) learning and assessment must be combined efficiently, like in the CMMI method; (4) practices deployment has to follow the transfer process of Szulanski. These requirements lead to an operational modeling of organizational capability around strategic objectives, by structuring its components (the practices) along a learning process.

\begin{tabular}{|c|c|c|c|c|c|c|c|}
\hline & \multicolumn{2}{|c|}{ Standpoint } & \multicolumn{3}{|c|}{ Capabilities Management Mechanisms } & \multirow[b]{2}{*}{$\begin{array}{l}\text { Examples of } \\
\text { methods }\end{array}$} \\
\hline & & $\begin{array}{c}\text { Process } \\
\text { independent } \\
\text { definition }\end{array}$ & $\begin{array}{c}\text { Operations } \\
\text { - strategy } \\
\text { link }\end{array}$ & $\begin{array}{l}\text { Transfer } \\
\text { tools }\end{array}$ & $\begin{array}{l}\text { Assessment } \\
\text { tools }\end{array}$ & Renewal tools & \\
\hline \multirow{2}{*}{ 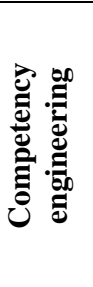 } & $\begin{array}{l}\text { Process } \\
\text { oriented } \\
\text { methods }\end{array}$ & No & Medium & Yes & Yes & $\begin{array}{c}\text { No } \\
\text { (normative logic) }\end{array}$ & $\begin{array}{l}\text { ISO, CMMI, } \\
\text { ITIL, SMEMP }\end{array}$ \\
\hline & $\begin{array}{l}\text { Resource } \\
\text { oriented } \\
\text { methods }\end{array}$ & Yes & $\begin{array}{l}\text { Weak to } \\
\text { Medium }\end{array}$ & $\begin{array}{c}\text { No } \\
\text { (no practices } \\
\text { definition) }\end{array}$ & $\begin{array}{c}\text { Yes } \\
\text { (sometimes non } \\
\text { systemic } \\
\text { aggregation) }\end{array}$ & $\begin{array}{c}\text { No } \\
\text { (no practices } \\
\text { definition) }\end{array}$ & $\begin{array}{l}\text { sarC, CRAI, } \\
\text { CSM, ECFM } \\
\text { (cf. section 2.1) }\end{array}$ \\
\hline
\end{tabular}




\begin{tabular}{|c|c|c|c|c|c|c|c|}
\hline 范 & $\begin{array}{c}\text { Orga. } \\
\text { Capability } \\
\text { methods }\end{array}$ & Yes & Strong & $\begin{array}{c}\text { No } \\
\text { (not } \\
\text { developed } \\
\text { enough) }\end{array}$ & Yes & $\begin{array}{c}\text { No } \\
\text { (not developed } \\
\text { enough) }\end{array}$ & $\begin{array}{c}\text { CBEA, CPX, } \\
\text { Capability } \\
\text { Framework }\end{array}$ \\
\hline
\end{tabular}

Table 1. Comparison of methods for managing Organizational Capability Approach

Moreover, the existing methods present some limits for the implementation of these necessary mechanisms (as figured in the Table 1). The assessment mechanism is supported by the three categories but the transfer mechanisms (the way to structure practices and deploy them with the aid of a model or guidelines) are only thought out in detail by process oriented methods. Ultimately, the renewal tools are not very instrumented, whereas they are essential to prevent a constraining standardization and to guarantee a sustainable innovation capability in the organizational capabilities management. Indeed, they are not really considered as the heart of the methods: either (1) they are opposite to a normative logic, or (2) the lack in practices definition avoids them being implemented or (3) the methods are not enough mature.

Finally, it is crucial to instrument the approach by providing an IT system. This will enable a systematic deployment of Organizational Capabilities, in order to help managers (1) at diagnosing its organizational status at different levels (What are the strengths and the weakness of the organization? Are different plants mature enough to work together? Can the firm produce the product anywhere with the same quality level?) (2) and at making decisions on the orientation of the organizational capability framework (What new capability does the firm need to develop? Can it profit from the progress of its plants to seize new opportunities and work on new projects?).

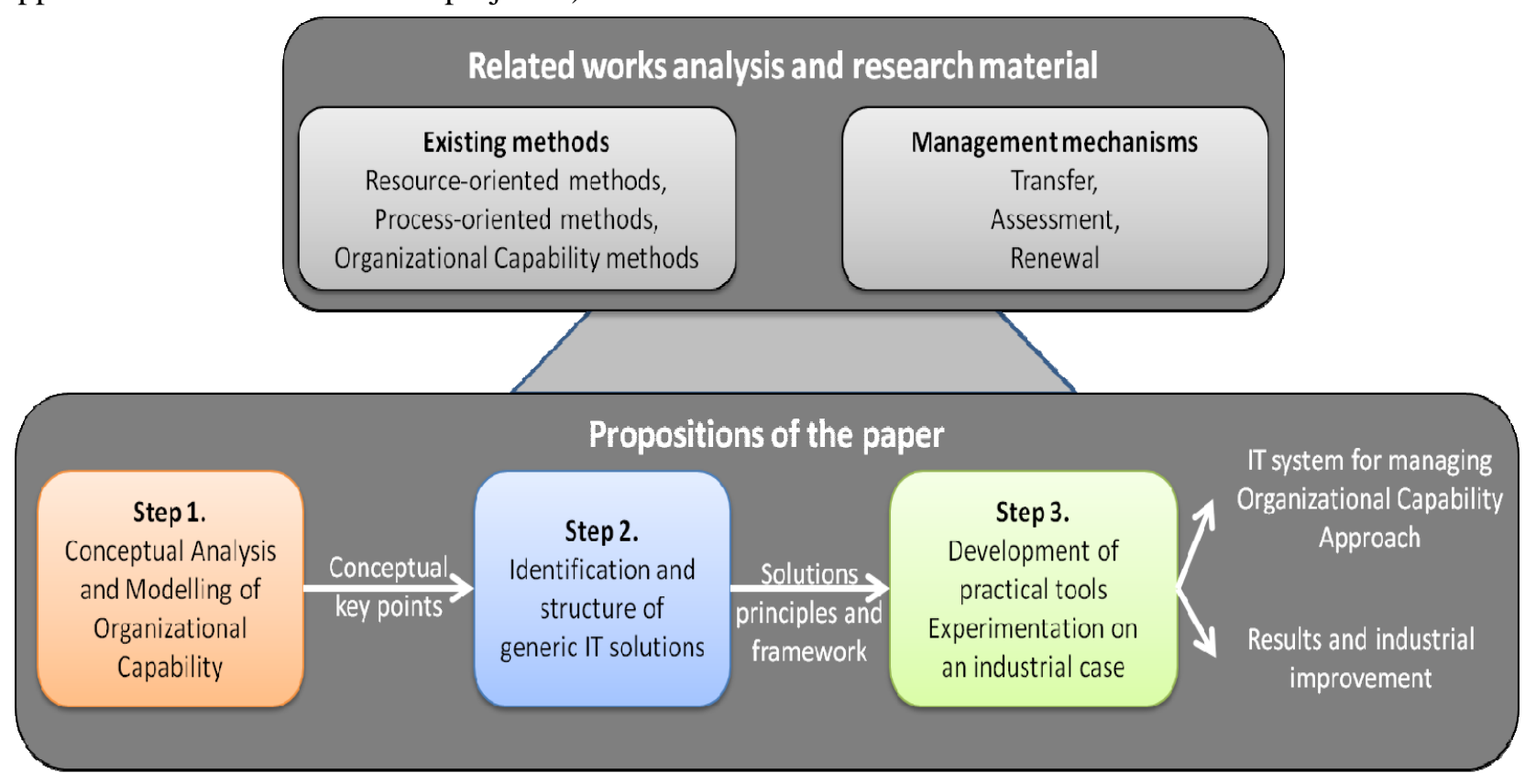

Figure 3. Our approach for developing and IT system for managing Organizational Capability Approach

In the following sections, the paper outlines our multi-disciplinary approach, mixing and synthesizing the value of research work and existing methods coming from management sciences and competency engineering.

First, a conceptual analysis and modeling is completed in order to consider all the aspects and the relationships which characterize organizational capability object. This conceptual modeling emphasizes some key points enabling us to overcome the aforementioned limits on the mechanisms for transfer, assessment and renewal. Then, the results of this conceptual phase are used to identify and structure generic IT solutions supporting the three management mechanisms. Then, this generic design of the IT system is 
specified on the industrial case of Valeo Group by proposing some concrete and practical solutions. All these propositions aim at supporting Organizational Capability Approach and helping managers in the implementation of this approach.

\section{The C-makers model for supporting Organizational Capability Approach}

This part proposes and explicates a formal model of the concept of organizational capability in order to gain an accurate understanding of this management object. This model will also emphasize the relations on which IT solutions could be proposed in order to enable better management and IT support of the approach.

\subsection{Structuring concepts}

The concepts supporting the three approaches (cf. 1.3) for managing organizational competencies are analyzed in order to extract the structuring elements for modeling the organizational capability concept.

\subsubsection{Concepts from resource oriented approach: focus on composition and assessment}

Many works from competency engineering (overviewed in section 1.3.2) propose models for managing individual, collective and organizational competencies: CRAI (Harzallah et Vernadat, 2002), sarC (Boucher, 2003), the competency systemic model, later referenced in the paper by CSM (Boumane et al., 2006), the extended competence framework model, later referenced in the paper by ECFM (Houé and Grabot, 2006) and UECML (Pépiot et al, 2007). These models differ considerably in their objectives and in their implementation: For instance, both CRAI and ECFM develop software based on their model in order to assess competencies and their adequacy to organizational needs as well as to identify the needs for training or qualification in correcting an inadequacy. CSM is more focused on the understanding of how an actor gathers knowledge and resources to build a dynamic competency according to a situation, and proposes some theoretical mechanisms to enrich the competency management. Nevertheless, some common concepts and relationships are shared by all these different works, and could be used for modeling Organizational Capability, particularly for explaining how it is composed and assessed.

\section{- The main objects:}

- Entity (Actor): All the models in the literature emphasize the notion of the actor, that is to say the entity (it could be an individual, a team, or a plant) which produces results by carrying out some activities and by putting into practice the competency it acquires. Some models keep this dynamic term (the actor is the one which acts), some others (like CRAI) prefer to deal with the static concept of "individual", by detailing its dynamic characteristic in the relationships with other concepts. The notion of "individual" always exists, whereas the definition of "actor" is dependent on and cannot be defined without "action". For the proposed model of Organizational Capability, the term "entity" is used: It maintains the static description given by the term "individual", and it can be understood at different levels, encompassing the notion of "individual" as well as any kind of group.

- Mission: This concept is also commonly used by the different approaches cited. This is the essential function of an entity. This term is often used on an individual level to detail the field of activities an individual has to master. This term also exists on a strategic, organizational level, to explain the long-term general objective of the organization. This long-term mission can be expressed in the achievement of some short-term operational objectives, in the obtainment of activity results. It is also expressed in the functional requirements of competency that an entity has to acquire.

- Aspect: Some models, like CRAI or the systemic model, use the concept of "aspect" to define the 
functional / knowledge area covered by the mission and which must be mastered by competency. Some other models, like ECFM, use the notion of roles based on the work of (Mintzberg, 1979) and (Hermosillo et al., 2005). Role is a group of functions that the entity has to achieve. These notions are quite symmetric: the entity plays different roles in order to achieve its mission, and the mission has several aspects that the entity must master. For the modeling of organizational capability, only the term "aspect" is maintained, to avoid semantic redundancy.

- Knowledge/Environmental resources: The authors did not come to a consensus for choosing the concept enabling to describe which elements the entity builds its competency from and use it. Some works consider that competency is only a construct built from knowledge, know-how, know-whom and know-be (CRAI, ECFM, UECML). Some others (sarC) represent competency rather as a means to link the entity with some environmental resources and do not give details of the knowledge used to create this link. Finally, CSM presents competency as a selection, a combination and a use of both knowledge and environmental resources. This point of view will be kept for the modeling of organizational capabilities, in order to distinguish between the "material" means (machines, software, collaborators etc.) and the "immaterial" means (knowledge, know-how etc.). Moreover, knowledge and resources can be on different organizational levels: A resource for a production service can be the $R \& D$ center or a machine, knowledge for the production service can be the quality policy of the group (such as TPM for Toyota) or the know-how of an operator on a specific machine.

- Situation: There is still a main concept shared by some models (sarC, CSM): the notion of "situation" consider the context (1) where the mission is achieved, (2) where the knowledge and the resources exist or not and are activated by the entity, (3) and also where the competency is implemented. A competency exists only if the situation enables its expression. For instance a medical team can cure some strong diseases in a fully equipped hospital but it would not be able to save its patients in a desert without tools.

\section{- The main relationships :}

- The required/acquired link: Competency is considered as the interface between mission and entity. This relationship is used to assess competency, by observing the adequacy between what an entity acquires and what a mission requires (similar to the qualification approach which assesses the adequacy between entity and process). As mentioned by (Berio and Harzallah, 2007), this assessment is based on strong hypotheses: required competencies must be clearly and completely defined in order to be coherent with the whole mission of the entity. Moreover, the proof (the guiding elements which are checked to verify if an entity has acquired competency) must be clearly and completely modeled. These hypotheses point out the great importance of the phase of competency design (focused on the definition of what the mission requirements are and how these requirements can be obtained) and assume that the expert designing the competency system is reliable. In addition, they do not take the notion of "situation" into account, which can cause some interference, even if the design phase is accurate. For example, a generic competency model can be applied for the training of medical teams; it would be sufficient for teams working in a hospital environment but not for those operating in desert conditions.

- The link with activity and the notion of result: Some models from the literature conserve a part of the process-based view of competency, linking activity and competency (sarC, ECFM). To some extent, activity can be considered as the use of the competency in a specific situation by an entity in order to achieve its mission. However, activity, in essence, is dynamic. In the modeling of organizational capabilities the static concept of result (as activity "product") is maintained. This concept, encapsulating the dynamic notion of activity, can also be used to provide an indicator on the "real" behavior of the capability in a situation and to potentially enable the identification of the limits due to the hypotheses presented above in the “required/acquired” relationship (Rauffet, 2009).

2.1.2 Concepts from process oriented approach: Focus on the organizational structure 
The quality methods supporting the process oriented approach are based on the creation and the deployment of good practice libraries such as ISO or CMMI, to guide organizations in the control or the maturity of their processes, or SMEMP for their projects (Gonzalez-Ramirez, 2008). Thus, they aim at organizing and assessing the organizational competencies of the organization around some key processes that are defined according to some recommendations (such as Part 4 of the ISO9000 norm) or even defined completely (such as the decomposition of CMMI in process areas). In order to detail how the previous concepts (aspect, mission, knowledge and environmental resources...) are structured in organizations, the process oriented approach provides some characteristics that enrich the modeling of organizational capability.

\section{- The main objects:}

- Operational and functional objectives: They differentiate operational and functional objectives in the achievement of the mission and focus on the fulfillment of the functional objectives. Indeed, a mission expects some results in a specific situation, and a mission also requires capabilities covering some of its aspects.

- Knowledge and process area: In order to structure the capabilities, the existing methods require and use the definition of the organizational processes (ISO9000), or define a set of process areas (CMMI) or knowledge area (SMEMP) a priori. It is a means to avoid forgetting an "aspect" of the mission given to the entity.

\section{- The main relationships:}

- General to specific decomposition: The mission is decomposed, from general objectives to specific objectives. Following Management by Objectives (Drucker, 1976), methods like CMMI or SMEMP use the notion of "general and specific requirements".

- "Axiomatic design"-like principles: The structure of the quality guide (ISO) or the maturity model (CMMI, SMEMP) differentiate and link the requirements (what the organization needs) from the practices (what the entities use in order to act), in an "axiomatic design" fashion (Suh, 2001). Practices are not always an operational means (they does not give details of which software, which machine or which tool must be used to improve the activities' performance), but they could constitute a guide (find a tool which can be used with such constraints, create and implement a method which answers such criteria etc. ) to meet requirements. To some extent, it is the way to detail how capability is acquired (guiding characteristic) and to provide the "proof" so as to check if the entity acquired the capability well (assessing characteristics).

The extracted concepts and the relationships from resource-oriented and process-oriented models are rather "static", focused on the structure of capabilities. The next section explores the dynamic aspects of Organizational Capability by pointing out the concepts related to the learning and improvement processes.

\subsubsection{Concepts from Organizational Capability Approach: dynamic learning and improvement}

The research works on good practice transfer, organizational learning and learning loops (cf. part 1.2) are then analyzed to extract clues on how to appreciate the management rules of organizational capabilities:

- Formal work/Practical work: Capabilities can be seen as the product of the formal work of experts (which gather and structure the organizational good practices around functional objectives) or as a contextualized means of action for entities (which use capabilities to ensure that their activities are successful and to achieve their operational objectives).

- The triple loop learning (transfer, feedback, practices sharing): On the one hand, capabilities requirements and practices are deployed on the operational ground according to some transfer mechanisms (Szulanski, 2006, Nonaka, 1994). On the other hand the learning entities use the capability structure to share their experience and some new good practices. According to (Le Boterf, 2003), who enriches the previous work of (Argyris and Schoen, 1978), the entity can either, (1) in a single loop, adapt its behavior to what is asked for, (2) in a second loop, propose some improvements on the requirements and practices the organization gives to it, or (3) in a socialized third loop, adopt the capabilities and share them with others. This triple loop learning is based on: 
- Learning schema and path dependency: The capabilities are acquired by entities by learning. For individual competencies, (Berio and Harzallah, 2007) refer for instance to e-learning techniques, for quality approach, some good practice libraries propose a structure to guide the learning (like CMMI or SMEMP, with the notion of maturity level). According to (Boumane, 2006), the learning dynamics can be captured in the notion of schema, that is to say the organization of learning elements such as operational invariants, inferences rules, etc. (Murray and Donegan, 2003). Moreover, the notion of maturity level is ultimately related to an intrinsic property of organizational capability: the path dependency. This explicates the status of organizational capability acquired by entities, which is dependent on the way (the different past states) the entities learn the capabilities (Metcalfe and Andrew, 2000).

- Contextual learning: As explained above, the capabilities must be deployed according to the situation of their potential use. That is why learning objectives (maturity level to reach, delay to achieve the functional objective) must be discussed beforehand. The capability structure therefore becomes a support for negotiating the efforts to be made between the organization and its entities. Furthermore, the situation also plays an important role in the capability acquisition, in considering the "triple loop" of Le Boterf (when entities adopt capabilities and share them with other). Entities can learn from others in order to progress more rapidly on the capabilities, by comparing their context similarities (Rauffet, 2009). Thus, they constitute CoPs (“Communities of Practice”, (Wenger, 2000)) around capability subject.

\subsection{The C-makers model}

As illustrated in Figure 4, the previous definitions of the structuring concepts enable us to build an organizational capability model, called C-makers (“C” for Capability, and "makers" for the other concepts which “make up” the capability).

\subsubsection{Conceptual synthesis}

The UML language was chosen to represent the model because of its understandability and its simplicity to be conceptually used by managers and software developers. This conceptual model will enable us to emphasize some key points and to structure new managerial and IT solutions, overcoming the limits identified in part 1.3 in the following parts.

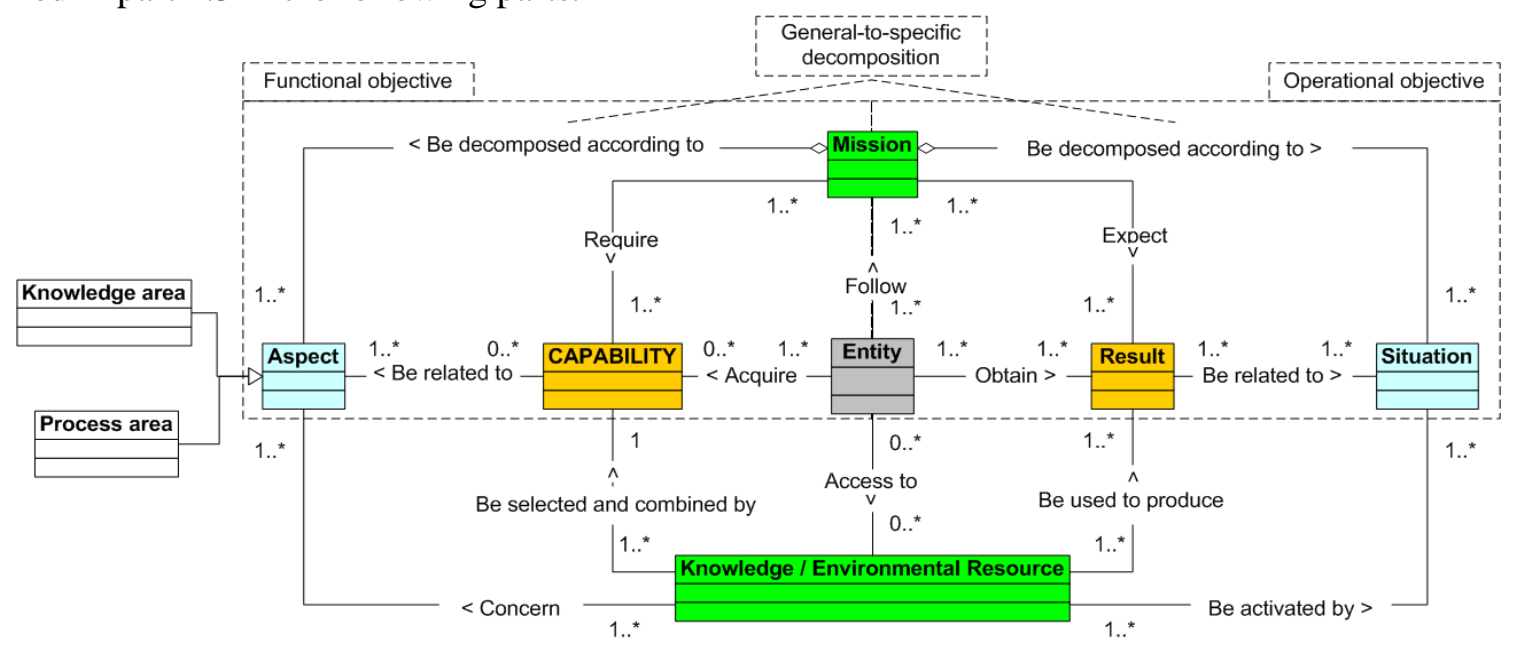

Figure 4: IT-based modeling of organizational capability - the symmetric C-makers model

As emphasized in the process oriented approach (dotted box in Figure 4), a mission (general objectives) can be decomposed (specific objectives) according to:

- some aspects, which are covered by one or more capabilities. This is a functional objective.

- some situations, where a result is expected. This is an operational objective. 
The entity follows the mission. It has to acquire the capabilities required and the results expected by the mission in a given situation. For this purpose, the entity can access knowledge and environmental resources. These can be activated or not in a given situation and they are selected and combined by the capabilities of the entity in order to obtain the results expected by the mission. Furthermore, these knowledge and environmental resources belong to an aspect, which can be a knowledge area (as in SMEMP method) or a process area (as in CMMI).

Another reading of the model can be made. The blue boxes (extreme left and right) underline the dichotomy between formal and real work. The orange boxes (left and right neighbors of "entity") differentiate potential and real performance. Finally, the green boxes (top and bottom) are the "function" and the "structure" elements of the "axiomatic" design of the capability.

\subsubsection{Key points}

This conceptual C-makers model represents the organizational capability object, and defines it completely by explaining its relationship to other structuring concepts. That emphasizes the key points for the management of the mechanisms presented in 1.2, and for overcoming the limits of section 1.3:

- transfer: the model underlines (1) the link between capability, knowledge and resources (to create the synergy), (2) the orientation of capability by mission (to define needs and to link with strategy), (3) the link between resources and aspects (to define necessary resources according activity domain), and the link between resources and situation (a capability can be deployed if the necessary resources are available on the local ground). These properties guide the design of patterns structuring practices (cf. 3.1.2 and 3.2.1) and emphasize the adjusted definition of learning objectives according to the situation.

- assessment: in addition to the set \{mission, entity, capability \} which allows for the evaluation of capability by the "acquired/required" relationship, assessment can be completed by studying the difference between acquired capability and obtained results. That will provide a means to diagnose the capabilities' effects and their coherence (not only the capability learning).

- renewal: the distinction between formal and real work outlines the existence of gaps that must be reduced with the aid of renewal mechanisms.

Nevertheless, this "static" conceptual study of the managed object must be completed by adding the dynamic elements of learning and improvement of section 2.1.3. Therefore, the next paragraphs focus on the practical use of this model in some IT solutions enabling the dynamic management of the Organizational Capability Approach.

\section{From conceptual model to IT framework for Organizational Capability Management}

Starting from the conceptual analysis resulting in the C-makers model and the dynamic aspects of section 2.1.3, the main functionalities of a generic IT system are defined and then structured. Then, the final paragraphs present concrete and technical developments used to support the implementation of Organizational Capability Approach. They are experimented in the context of a French national research project and the industrial case study of Valeo Group.

\subsection{Functionalities and IT structure}

First of all, the system's users are defined. Then, the main functionalities of the system are specified. Each management mechanism (transfer, assessment, renewal) is supported by an IT solution, which is justified with conceptual relationships emphasized in specifications of some parts of the C-makers model. 
In order to conserve the link between strategy and operations, the system must be accessible to managers at different organizational levels. Moreover, communication and dynamic management should be implemented between them.

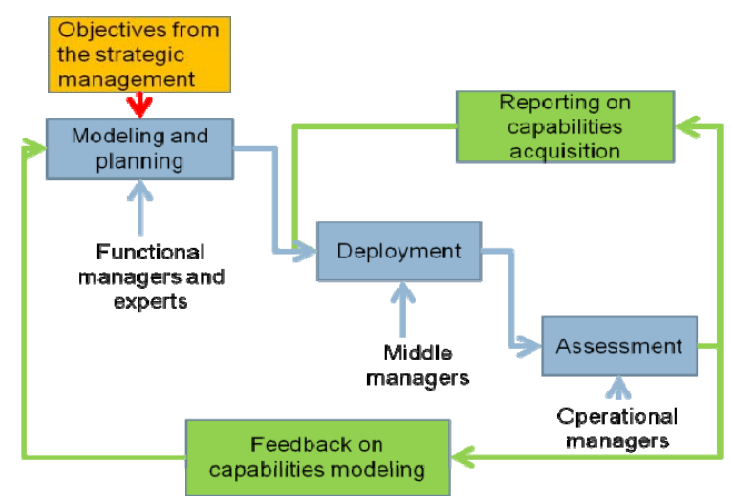

Figure 5. System users

These users can be categorized according to the Szulanski transfer process:

- The Functional Managers are responsible for the adaptation of the acquired practices around defined organizational capabilities (strategy managers choose capabilities to develop, and functional experts translate them by structuring a set of identified good practices that operational ground has to acquire);

- The Middle Managers are responsible for the application of organizational capability patterns (they transmit the structured good practices to the local ground by adjusting the context of application and the learning objectives);

- The Operational Managers are responsible for the acceptation and the appropriation of organizational capabilities on their local ground. They also have to boost learning and improvement to enrich the modeling of organizational capabilities by functional managers and to adapt the objectives defined with the middle managers (to guarantee the double loop learning that is necessary for renewal).

3.1.2. Main functionalities to implement a dynamic management of Organizational Capabilities

The three management mechanisms are reviewed to provide them with generic IT solutions.

- Transfer: As illustrated in Figure 6, a part of the C-makers (represented by the transparent background, an excerpt of Figure 4) is specified to design the pattern for modeling organizational capabilities, that is to say, for structuring practices around strategic objectives. The pattern combines learning and evaluation logic in order to ease its transfer (between functional, middle and operational managers) but also its operational assessment:

- the class "aspect" is decomposed into some "levers of action" (which are the elements of aspects on which capability development can be supported);

- other dynamic learning aspects (synthesized in 2.1.3) are added to this specification. Thus the class "schema" is based on the "learning path" (which follows the property of path dependency) which is composed of different "maturity levels".

- capability requirements stand at the intersection of "levers of action" and a "maturity levels". Indeed, each lever is allocated with an objective for each level. Finally, a set of practices composes a capability requirement in order to detail and prove its achievement.

This generic structure for gathering practices around organizational capabilities and enabling their deployment is specified in the section 3.2.1 on a specific pattern called roadmap. 


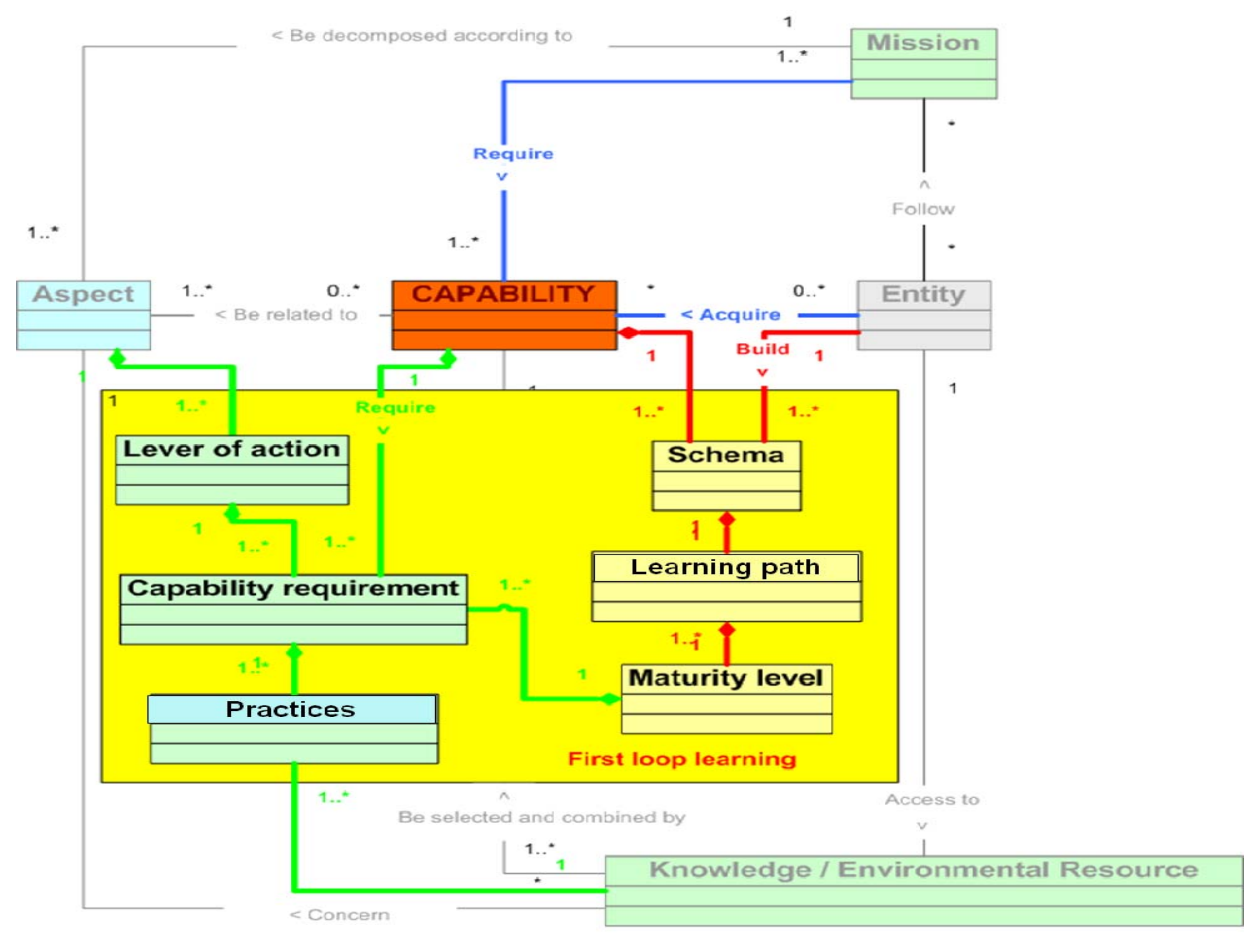

Figure 6. Transfer patterns for structuring Organizational Capability with practices

- Assessment: The multi-level consolidation of capability measurements is guaranteed by the multi-level property of the entity (it can be a plant, a division or the whole company) as well as the links with aspect and mission which enable aggregation by functional networks, by product or geographic zone (cf. Figure 6).

Moreover the C-makers model highlights the possibility to enrich capability assessment by using the difference between capability and results. This point of view (illustrated in Figure 7 specifying a part of the C-makers model) consists in considering and assessing capability, not only as the product of the learning process but also as a factor explaining the performance a plant gets.

This stresses the need to adopt decision support systems able to cross data: (1) capability assessments could therefore be compared with operational performance indicators on different levels to estimate if the implement capability is efficient and coherent with the operations; (2) this coherence could be also studied with informational information to find explicative factors of some singular behavior.

This approach will be developed in a specific tool called "Perf\&CoP Manager" and presented in 3.2.2.

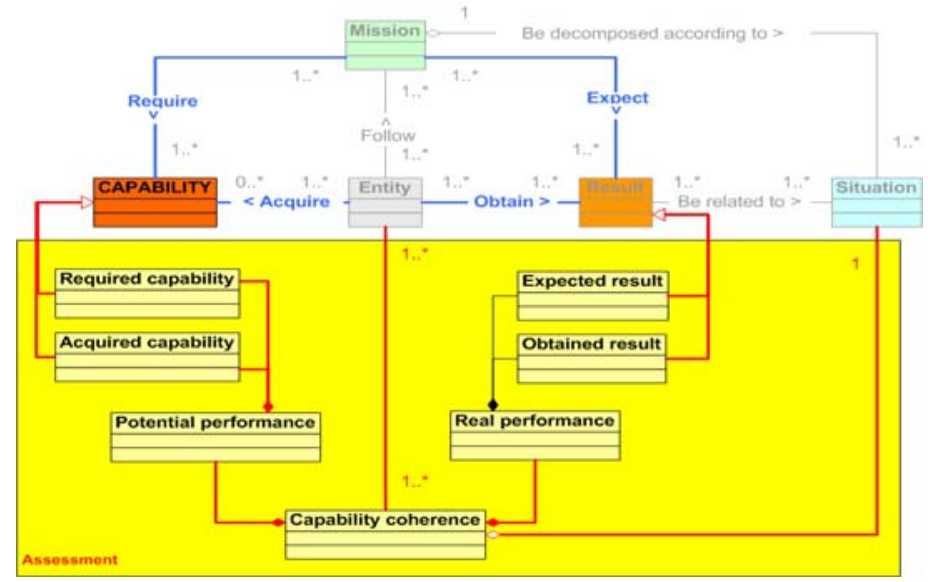

Figure 7. Organizational Capability Coherence assessment for passive feedback

- Renewal: The most obvious solutions to support renewal are the dialog between local and middle managers (who can regularly negotiate the learning objectives) and a feedback management system (that would enable 
to gather and bring up issues or recommendations from operational managers to functional managers). They could respectively support Argyris' first and second learning loops. Nevertheless, active feedback is not always easy to maintain. Moreover, a third loop must also be created to allow for innovation, recycling practices and mutual learning, as proposed by Le Boterf.

To remediate to an occasionally deficient second loop, capability coherence could be used to supply passive feedback. Indeed, it is a way of knowing if the capabilities are really appropriate and generate interesting effects (information that classical capability assessment, overly focused on the learning and acquisition process, does not provide). Furthermore, the use of situational information (context, product type, seniority) with this capability could constitute criteria to constitute CoPs (emerging from the same concerns in the same context) and launch more targeted animation. These elements are also developed in the "Perf\&CoP Manager" tool of section 2.3.2.

\subsubsection{IT structure design}

In a generic way, we structured the previous proposed IT solutions, as depicted in Figure 8. The elements related to transfer mechanisms are drawn in green, the ones related to assessment mechanisms are in red, and the ones related to renewal mechanisms are in yellow. The core of the generic structure is an engine linking a database, where organizational capabilities could be stocked, and a server which enables us to make requests. Around this core, the solutions supporting the three management mechanisms are structured:

- Transfer and Daily Data Management: A client-server relationship allows for the daily management of Organizational Capability Approach. It supports the interactions of the three categories of managers who can explore the database (at this step access rights have not been thought out yet: it is hard to foresee if progress visibility by all entities is an incentive lever or a paralyzing comfort). Furthermore, the managers have different writing access rights: (1) functional managers propose and correct patterns, (2) middle managers allocate the patterns to entities and define learning objectives, (3) operational managers regularly assess the patterns in order to inform upon the local acquisition of organizational capability and they can also give their feedbacks on the system.

- Assessment and Periodic Data Management: A server-server relationship allows for the periodical export of data which could be consolidated for other usages. For instance, local assessment can be aggregated weekly or monthly in business intelligence tools and then provide specific indicators for managers on requested organizational perimeters. Moreover, other indicators coming from tools like ERP can be crossed with the organizational capability learning indicators to provide new pertinent information, as previously suggested.

- Renewal and Periodic Data Mangement: Active user feedback can be periodically synthesized and pushed to functional managers for correction. Finally, the passive feedback (built from consolidated capability coherence indicators) could also be useful for creating participative and community innovation by listing singular entities or constituting CoPs. 


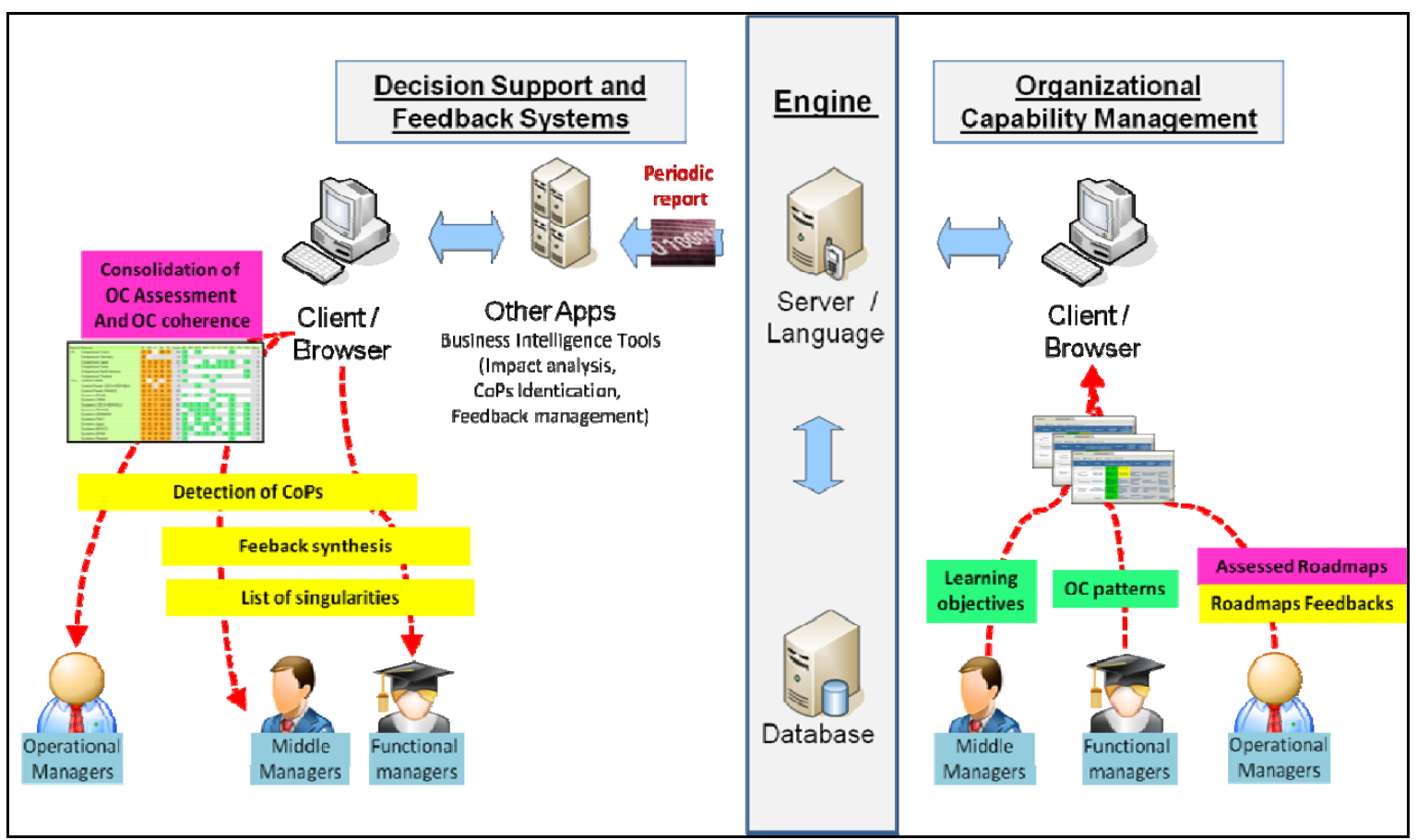

Figure 8. IT structure for Organizational Capability Management

\subsection{The Valeo Experiment}

The Valeo group is a well known automotive supplier, present in 28 countries and employing around 70, 000 people. It has been looking into integrating the Organizational Capability Approach in its management system for 4 years. It has to manage about 50 strategic Organizational Capabilities required by 6 functional networks (Information Systems, Production Systems, People Involvement, Quality Systems, Supplier Integration and R\&D - Constant Innovation) in about 120 plants.

In this context, research and industrial works were carried out within the Pilot2.0 project supported by the French National Agency of Research (ANR, 2007). It involves laboratories (IRCCyN and M-LAB), companies (MNM Consulting and Valeo) and institutional partners (Vaucluse County Council). The aim of this partnership is to provide a generic methodology and a platform for the management of organizational capabilities in distributed organizations. The following paragraphs present how a platform is specified according to the previous model C-makers - to enable the mechanisms of transfer and assessment and how a complementary module is added to create the second and the third learning loops and to support the Organizational Capabilities' renewal. These IT solutions have been specified by the Valeo group and their implementation - over the three last years - illustrates the paper’s developments.

\subsubsection{Transfer and assessment of an Organizational Capability for deploying an IT network}

First of all, it is necessary to provide a pattern that structures practices enabling the modeling of organizational capabilities, their deployment (by ensuring a dialog between the three kinds of manager) and finally to guide and assess their development on local ground. Figure 9 represents a short excerpt of a Security Roadmap used by Valeo. The capability pattern takes the form of a matrix called roadmaps, designed by (Monomakhoff and Blanc, 2008). Figure 9 underlines the different elements by linking them with the specification of the C-makers made in Figure 6.

In this example, the requirement "security deployment is planned" is achieved when three practices are completed (on coordinators appointment, armbands order, and training modules writing).

The roadmap is self-assessed by operational managers. This assessment follows the logic of "front progression": all practices of a capability requirement must be validated to achieve this requirement and all 
the capabilities requirements of a maturity level must be achieved to overcome the level. This assessment logic forces managers to look for coordinated progress on all the aspects of the capability

On the security roadmap example, the acquisition and the development of tools and standards are not sufficient to acquire the capability; if he/she wants to overcome level 1 or 2, the manager has also to take into account the information and the training of the employee on the security tools.

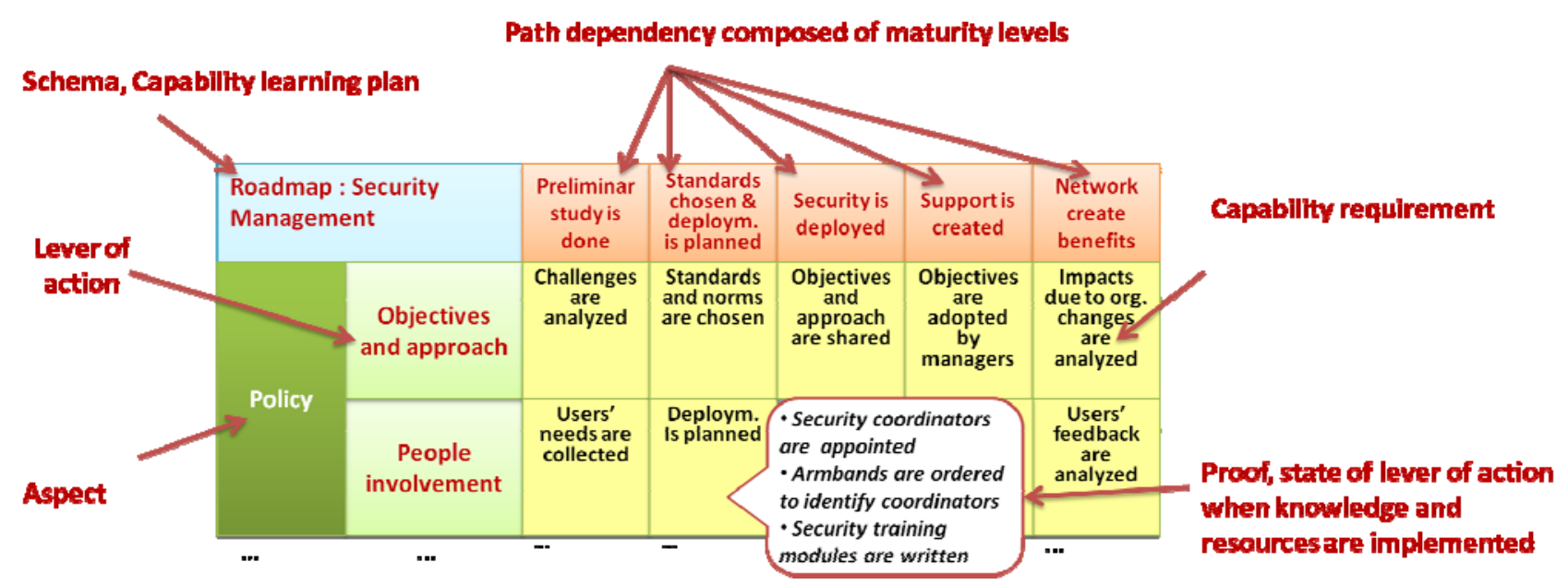

Figure 9. Excerpt of a security roadmap (specific Organizational Capability pattern)

All these measures are consolidated at the different group levels, to give an overview of the maturity levels reached by a site, a business unit, a functional network, or the whole group, as emphasized in Figure 10.

On the example of security roadmaps, only $20 \%$ of Eastern European plants of the group succeeded in passing the maturity level 2, whereas all these plants acquired all the practices of levels 1 and 3 .

So roadmaps enable to manage organizational capabilities by assessing them according to the "acquired/required" relationship. Moreover, it proposes a double learning loop with

\begin{tabular}{|l|c|c|c|c|c|}
\hline \multicolumn{1}{|c|}{ Zones } & $\mathbf{1}$ & $\mathbf{2}$ & $\mathbf{3}$ & $\mathbf{4}$ & $\mathbf{5}$ \\
\hline $\begin{array}{l}\text { Western } \\
\text { Europe }\end{array}$ & & & & $30 \%$ & \\
\hline $\begin{array}{l}\text { Eastern } \\
\text { Europe }\end{array}$ & $20 \%$ & & & \\
\hline $\begin{array}{l}\text { North } \\
\text { America }\end{array}$ & & & & & \\
\hline $\begin{array}{l}\text { North } \\
\text { Africa }\end{array}$ & & $90 \%$ & $60 \%$ & & \\
\hline
\end{tabular}

Figure 10. Consolidated assessment on geographical zones the implementation of a feedback system (based on a wiki platform). Nevertheless, issues have been identified in the context of Valeo (Fall and Rauffet, 2008) about people involvement and their participation in the third feedback process.

For more than one year, Valeo's middle management did not understand why Eastern Europe was not "capable" of security, and they had no local feedback on this issue. A later audit explained that the practice on "armbands" actually had a negative connotation in this geographical zone (because of a historical and political past) and prevented the plants from progressing in their learning.

It is therefore necessary to reinforce this second loop (to have "vertical ascending many-to-one" communication) and, in addition, create a real third loop (to support the "horizontal many-to-many" collaboration).

\subsubsection{Enriched assessment and renewal around this IT nework Organizational Capability}

The two identified limits in the implementation of the previous system are:

- the capability assessment based only on the "acquired/required" relationships but not linked to the study of the capabilities effect on real performance.

- a deficient second loop, due to the weak participation of operational users in the feedback process, which does not provide enough information on the situation of learning and use of the capability.

In order to overcome these limits, an additional module was designed, called Perf\&CoP Manager. It currently 
takes on the form of a demonstrator. It uses Valeo data and it is tested on scenarios in order to demonstrate its validity. Its development is based on VBA and some Google APIs, in order to facilitate data manipulation and future integration into the Roadmapping platform. The security roadmap is once again taken to illustrate its functioning. This module provides:

- Impact analysis: By crossing the assessment of capabilities with the assessment of results, based on statistical dependency methods (Rauffet, 2009), in order to analyze the impact of capabilities on real performance. It therefore provides a means of detecting if a roadmap accurately models an organizational capability, without unexpected negative side effects on some performance indicators (cf. Figure 11, blue box).

The security roadmap has a positive influence by decreasing the number of occupational accidents. On the other hand, it has a secondary negative effect and seems to currently reduce the production rate. The practices structured in the roadmap must be reviewed (requirements on the continuous presence of a security officer or the frequency of security controls could be changed).

- Singularities' analysis and passive feedback: By enriching the sometimes deficient active users' feedback (the second learning loop) with some passive information. Because people do not always speak about their operational problems, the analysis of the behavior of a roadmap on all the entities according to a performance criterion (chosen by an expert or obtained by the impact analysis) provides a way to detect entities with outperformance or underperformance. As emphasized in the green box of Figure 11, the manager can manually determine the zones of regular and singular performance, by choosing filters (he can choose a specific geographical zone or a product branch) and listing the entities which show unexpected behavior.

The behavior of plants is analyzed by comparing their assessment of the security roadmap and their frequency rate (an indicator characterizing the occupational works). In addition to the entities from Eastern Europe (frozen at the $2^{\text {nd }}$ maturity level due to the non adapted armband's practice), a French plant also presents singular behavior. The former acquired all the practices of the first three maturity levels, but it has a bad frequency rate in comparison with the other plants with the same capability level. This identified situation requires a particular audit or a targeted animation on this kind of plant. This will enable to find the factors of this singularity (for instance, it could be due to an assessment erro, or to the absence of implicit practice that other plants possess by default and that is not written in the roadmap).

- Communities of Practices - Research and Creation: From the analysis of singularities or by acting on the filter tools (result indicators, situation properties), some entities can be grouped in order to create a real third learning loop (cf. green and red boxes of Figure 11). It is one way of proposing local collaborations (1) between regular neighbor entities (similar in performance or/and in situation) to increase capability acquisition speed, (2) between singular and regular entities, to solve the problems of singular entities by following the example of regular entities (3) or between singular entities, to make them think about the causes of their problems and to see if it is a problem related to the adaptation of roadmaps in certain situations or to detect opportunities in order to enrich roadmaps through new good practices in the case of outperforming entities.

The French plant (producing air conditioning systems) is invited to join a Community of Practice with other plants sharing the same security roadmap level, the same product, some other similarities (language, geographical zone, seniority...) and having a better frequency rate. So the French plant can ask other CoP members if they implement implicit practices not written in the roadmap. It can also get some advice from others to progress more efficiently and more quickly on a level it has difficulties to achieve. Moreover, the middle manager responsible for a group of entities, who observes that some of them are singular on the security roadmap, could create a specific CoP and launch targeted actions to unlock this issue. 

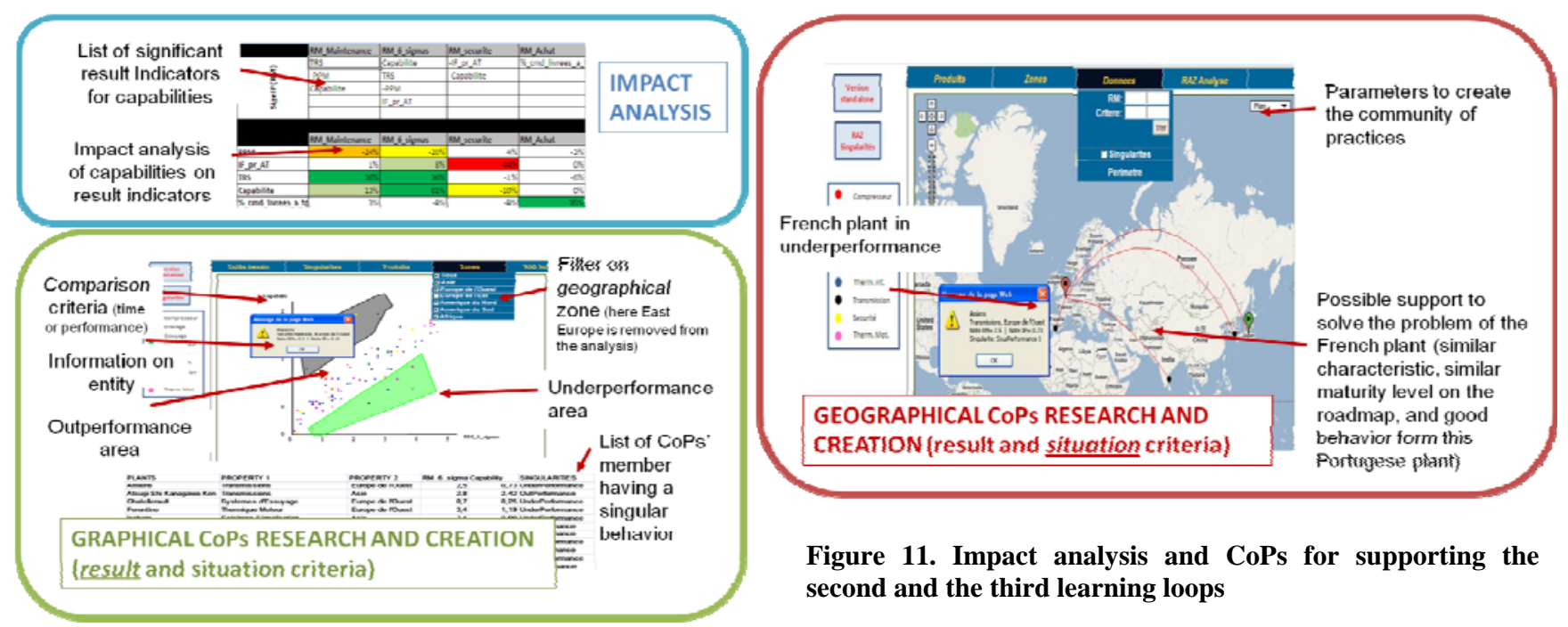

Figure 11. Impact analysis and CoPs for supporting the second and the third learning loops

\subsubsection{Results analysis}

The Figure 12 summarizes the specific IT solutions deployed in Valeo group by integrating them into the generic IT structure (cf. Figure 8).

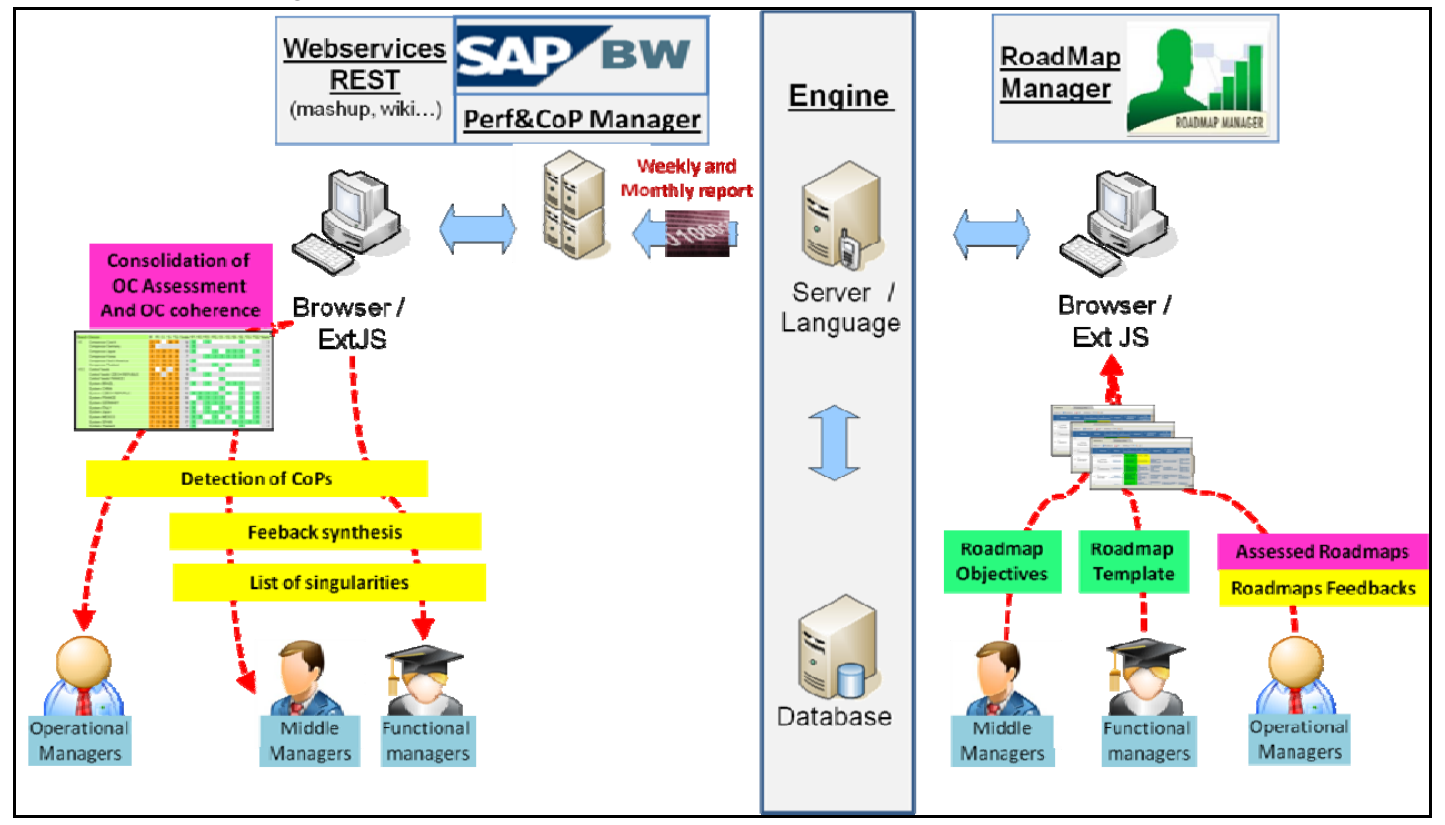

Figure 12. IT Specific Valeo IT structure for Roadmapping

This platform instruments the three management mechanisms:

- transfer: Roadmap Manager is a platform which stocks roadmaps and supports transfer and assessment mechanisms (by allowing navigation, edition, assessment, and addition of commentaries).

- assessment: SAP BW is the decision support system chosen by Valeo. It supports the weekly and monthly consolidation of data on different organizational perimeters. It could also feed some mash-up applications (widget presenting scorecards in iGoogle for instance).

- renewal: Last of all, the wiki platform gathers and synthesizes feedback on capability requirements or practices considered as difficult to acquire). Moreover, the proposed Perf\&CoP manager is integrated into this framework to enable vertical and horizontal improvement.

The first feedback of Valeo is positive:

- On the use of roadmaps for supporting transfer and assessment mechanisms in Organizational Capability Approach management: 
- A survey led within Valeo Group in 2008 (Fall and Rauffet, 2008), using the interview of 40 operational and middle managers belonging to different industrial branches, shows that $74 \%$ of managers consider that the roadmaps make the good practices repositories explicit and accessible. Moreover, for $87 \%$ of middle management, it is also a tool for better understanding and driving organizational progress. In summary, roadmaps enable them to capitalize on and make good practice libraries operational. It is also a way to introduce new practices more rapidly, such as the green IT approach (AIM, 2010); last of all, it allows the fast integration of newcomers in its organization, and it improves the control of operational excellence and organizational cohesion by providing some useful consolidated data (Fall, 2008).

- In a quantitative way and according to the quality managers of Valeo (HSQE, 2009), the use of roadmaps is directly responsible for up to a $50 \%$ decrease of faulty "parts per million" in some plants of the group, which is an important indicator for an automotive supplier.

- From a managerial viewpoint, François Blanc, Valeo’s Director of Information Systems, signalled the use of a roadmap as a means to give functional objectives in addition to the operational objectives. This enables the plant to have a long-term view of the strengths and weaknesses of an entity, in addition to the short-term performance view. An entity could have, for instance, good financial indicators over a shortterm period, if a manager reduces investments, training and resources for process and product innovation. However, this reduction can trigger bad performance, because there are not enough resources. Roadmaps are therefore a means of controlling the sustainable "good health" of entities and not only their apparent "fitness".

- On the interest of the Perf\&CoP manager module for creating or reinforcing the renewal mechanisms:

- The same Valeo survey in 2008 shows than more than $60 \%$ of operational managers consider the roadmap system as a reporting tool. $65 \%$ of them use the system once a month or less, and do not use (or even do not know) the feedback functions. One of them explains this deficient renewal process by a lack of time and the distance with functional managers ("We do not speak with God!" he joked).

- The first implementation of this complementary module on scenarios shows the advantages for users to detect and to correct the problems in Organizational Capability management more rapidly, (1) by studying the side effects of roadmap patterns, (2) by identifying the contextual factors generating these issues, (3) and by boosting participative innovation by creating local communities of practices.

\section{Conclusive Discussion}

This paper is part of research works into the Organizational Capability Approach. This offers a standpoint which is not oriented by process definition and which is at an organizational level by nature. To some extent, this approach enables us to overcome certain criticisms addressed to current engineering competency methods.

The propositions defended by the article bring contributions:

- on conceptual, managerial and IT levels: C-makers model structures concepts around Organizational Capability to improve the understanding of the managed object, and resulting IT solutions provide a complete framework for supporting the management mechanisms (transfer, assessment and renewal of Organizational Capability Approach).

- on an industrial level: this conceptual material enabled the specified design of the roadmapping platform and the additional module Perf\&Cop Manager. These very complementary IT solutions constitute for Valeo managers an operational toolbox, which covers all the dimensions of organizational capability management. All or part of these tools have already been tested in the Valeo group context and give some encouraging results. The knowledge and resources of the company are really capitalized around the approach: Good practices are identified, used and recycled more efficiently (before they were only gathered by functional managers on some static guides that stayed sometimes at the back of the cupboard) and a real organizational learning process is implemented to federate all Valeo's plants. 
However, these propositions are based on a hypothesis which limits the implementation perimeter of the Organizational Capability Approach:

- Study perimeter: the paper only studies the case of globalized organizations (distributed, multi-level, multiproduct, multi-functional context) who control their organizational entities. Organizational capabilities are therefore managed in an intra-organizational way. Is it possible to translate the propositions to a more local context or in extended enterprise with a network of entities where the control is harder to maintain?

- Data quality: The concrete use of capability coherence assessment is submitted to the quality of available information which should be a parameter to consider the pertinence of the proposed decisional tools.

Further works could explore new perspectives:

- on scientific and managerial levels: a bridge must be built between Organizational Capabilities Approach and individual competency methods to align completely competency management with strategy.

- on industrial level: Future work will continue to generalize on the validation of the additional module in the context of the Valeo group and other similar companies.

\section{Acknowledgements}

The authors would like to thank the ANR (National Research Agency) which supports the Pilot2.0 project, as well as François Blanc (Director of Information Systems of Valeo group), Nicolas Monomakhoff (Head of MNM Consulting), Ibrahima Fall (ex-PhD student in MNM Consulting), Roland Alech (Project Manager in MNM Consulting) and Michel Labrousse (headof the Research Department in MNM Consulting), who provided their precious advice and shared their operational experience of the roadmap to build scientific and pragmatic models and frameworks for managing organizational capabilities.

\section{References}

1. Porter, M. E., 1979. How Competitive Forces Shape Strategy. Harvard business Review

2. Harzallah, M., Berio, G. \& Vernadat, F. (2006). Modeling and analysis of individual competencies to improve industrial performances, IEEE Trans. on Systems, Man And Cybernetics, 36:1.

3. Boucher, X., Bonjour E., Grabot B., 2007. Formalisation and use of competencies for industrial performance optimisation: A survey. Computers in Industry 58 98-117

4. Grant, R. M., 1996. Prospering in dynamically-competitive environments: Organizational capability as knowledge integration. Organizational Science , 375-387

5. Hamel, G., \& Prahalad, C. K., 1990. The Core competence of the Corporation. Harvard Business Review , 68 (3), 79-93

6. Szulanski G., Jensen R.J., 2006. Presumptive adaptation and the effectiveness of knowledge transfer. Strategic Management Journal, Vol.27

7. Saint-Amant G.E., Renard L., 2004. Premier référentiel de connaissances associées aux capacités organisationnelles de l'administration électronique. Management International, Vol.9

8. Hoopes, D. G., Madsen, T. L., \& Walker, G. (2003). Guest Editors' Introduction to the Special Issue: Why is there a Resource-Based View? Toward a Theory of Competitive Heterogeneity. Strategic Management Journal , 23, 889-902

9. Barney, J. B., 1991. Firm Resources and Sustained Competitive Advantage. Journal of Management , 17 (1), 99-120

10. de Pablos P.O., Lytras M.D., 2008. Competencies and human resource management: implications for organizational competitive advantage. Journal of Knowledge Management, Vol. 12, Issue 6

11. Lorino, P., 2001. Méthodes et Pratiques de la Performance, Editions d'Organisation

12. Lebas, M., 1995. Oui, il faut définir la performance. Revue française de comptabilité , 69, 66-72

13. Rauffet, P., Da Cunha, C., \& Bernard, A., Labrousse, M., (2009). Progress management in performancedriven systems: study of the 5 steps roadmapping, a solution for managing organizational capabilities 
and their learning curves. 13th symposium IFAC on Information Control Problems in Manufacturing. June 2009, Moscow

14. Vaudelin, J.P., 2002. La compétence collective en quête de significations, 1er colloque GCCGI, Nantes, December 12-13.

15. Sanchez, R. et al., 1996. Dynamics of Competence-based Competition, Elsevier Science Ltd.

16. Amherdt, C.H., Dupuich-Rabasse, F., Emery, Y. and Giauque, D. (2000). Compétences collectives dans les organisations, Presses universitaires de Laval.

17. Cullen Coates, 2008, Managing Organizational Competencies. On http://cullencoates.com/images/Managing_Organizational_Competencies_.pdf

18. Senge P., 1990. The Fifth Discipline: The art and practice of the learning organization. Doubleday

19. Garvin, D., Edmondson, A., and Gino, F., 2008. Is yours a learning organization? Harvard Business Review

20. Yeung, A., Ulrich, D., Nason, S., 1999. Organizational learning capability. Oxford Press

21. Diani, M., 2002. Connaissance et performance économique :Une nouvelle vision de la firme dans une économie basée sur la connaissance. Aix-Croisées Scientifiques (ACS) : Connaissance(s) et Incertitudes. Aix-En-Provence

22. Nonaka, I., 1994. A dynamic theory of organizational knowledge creation. Organization Science

23. SEI, 2011. CMMI website. http://www.sei.cmu.edu/cmmi/

24. Guillevic, C., 1993. Psychologie du travail. . Nathan Université

25. Argyris C., Schoen D., 1978. Organizational learning: A theory of action perspective, Addison Wesley

26. Burke, W., \& Litwin, G., 1992. Causal Model of Organizational Performance and Change. Journal of Management

27. Le Boterf, G. 2000. "L'ingenierie des competences," Second Edition. Paris: Editions d'organisation.

28. ITIL, 2011. ITIL Home. Consulté le Juillet 2010, on http://www.itil-officialsite.com/home/home.asp

29. Gonzalez-Ramirez, Marle F., Bocquet J.C., 2008. Assessing project maturity : a case study, PMI Research Conference, Poland

30. Armistead C., 1999. Knowledge management and process performance. Journal of Knowledge Management. Vol. 3, Issue 2.

31. Mc Clelland, D., 1973. Testing for Competence Rather than Intelligence, American Psychologist.

32. Harzallah M., Vernadat F., 2002. IT-based competency modeling and management: from theory to practice in enterprise engineering and operations, Computer In Industry, Issue 48.

33. Boucher X., 2003. Formal diagnosis of multi-enterprises systems of competencies. ICE Conference.

34. Bonjour, E., Dulmet, M., Lhote, F., 2002. An internal modelling of competency, based on a systemic approach, with socio-technical systems management in view, Proc. of IEEE International Conference on Systems, Man and Cybernetics, SMC'2002, Hammamet, Tunisia

35. Houé B., Grabot B., Geneste L., 2006. Competence management for business integration. $12^{\text {th }}$ INCOM Conference.

36. Hiermann W \& Hôfferer M., 2003. Hiermann W \& Hôfferer M. , 2003, A practical knowledge-based approach to skill management and personnel development, Journal of Universal Computer Science, Vol. 9 N. 12

37. Tarafdar M., Gordon S.R., 2007. Understanding the influence of information systems competencies on process innovation: A resource-based view., Journal of Strategic Information Systems, Vol.16, Issue 4, December 2007, Pages 353-392

38. Webb M, 2006, “Capabilities-Based Engineering Analysis (CBEA)”, international conference of complex systems 
39. Duhan,S. Levy, M and Powell, P, 2005, "IS Strategy in SMEs Using Organizational Capabilities: The CPX Framework”, In Proceedings of 13th European Conference on Information Systems, Regensburg

40. Boumane A., Talbi A., Tahon C., Bouami D., 2006. Contribution à la modélisation de la compétence. MOSIM Conference.

41. Pépiot G., Cheikhrouhou N., Furbringer J.M., Glardon R., 2007. UECML: Unified Enterprise Competence Modelling Language. Computer In Industry, Issue 58

42. Berio G., Harzallah M., 2007. Towards an integrating architecture for competence management.Computer In Industry, issue 58.

43. Mintzberg,. H., 1973. The structuring of organisations, Prentice Hall.

44. Hermosillo W., J., Chatha, K.A., Weston, R.H., Aguirre, O. and Grabot, B., 2005. Implementation and optimisation of ERP Systems: A Better Integration of Processes, Roles, Knowledge and User Competences, Computers in Industry, 56(6), 619-638

45. Drucker P.F., 1976. What results should you expect? A users' guide to MBO. Public Administration Review. February.

46. Suh N.P., 2001. Axiomatic Design: Advances and Applications, Oxford University Press

47. Drucker, P.,1957. La pratique de la direction des entreprises. Éditions d’Organisation

48. Suh, N. P., 2001. Axiomatic Design: Advances and Applications. Oxford University Press

49. Murray P., Donegan K., 2003. Empirical linkages between firm competencies and organisational learning. The learning Organization. Vol. 10 Issue 1

50. Metcalfe, S.J., Andrew J., 2000. Knowledge and capabilities: Resources, Technology and Strategy. Foss and Roberston, London and New York

51. Wenger, E., 2000. Communities of practice and social learning system. Organization, Vol. 7 Issue 2

52. ANR, 2007. ANR-07-TLOG-016, Pilot2.0 : Méthodes et composants pour la mise sous contrôle des capacités organisationnelles et pilotage des plans de progrès dans les organisations étendues.

53. Monomakhoff, N., Blanc, F., 2008. La méthode 5Steps ${ }^{\circledR}$ : Pour déployer efficacement une stratégie. AFNOR

54. Fall, I., Rauffet, P., 2008. Impacts of the use of organizational capabilities and roadmapping at Valeo Group. internal resource from MNM Consulting

55. Fall, I., 2008. La capacité comme objet de gestion : genèse, mode d'emploi et enjeux à travers une expérience pionnière de mise en gestion systématique des capacités organisationnelles, ACFAS 4e ed.

56. AIM, 2010. Keynote speech from N. Monomakhoff and F. Blanc on the Valeo's experience of roadmapping. Association Information et Management. La Rochelle

57. HSQE, 2009. Interview of Nicolas Monomakhoff on 5 step roadmapping. http://www.wkhsqe.fr/actualites/detail/14950/rythmer-sa-progression-en-5-steps.html 